Research Article

\title{
Experiment and Prediction of Ablation Depth in Excimer Laser Micromachining of Optical Polymer Waveguides
}

\author{
K. F. Tamrin $\mathbb{D}^{1},{ }^{1}$ S. S. Zakariyah, ${ }^{2}$ K. M. A. Hossain, ${ }^{3}$ and N. A. Sheikh $\mathbb{D}^{4}$ \\ ${ }^{1}$ Department of Mechanical and Manufacturing Engineering, Faculty of Engineering, Universiti Malaysia Sarawak (UNIMAS), \\ 94300 Kota Samarahan, Sarawak, Malaysia \\ ${ }^{2}$ College of Engineering and Technology, University of Derby, Derby DE22 3AW, UK \\ ${ }^{3}$ School of Electrical, Mechanical, and Mechatronics System, University of Technology Sydney, Ultimo, NSW, Australia \\ ${ }^{4}$ Department of Mechanical Engineering, Faculty of Engineering and Technology, HITEC University, Islamabad, Pakistan
}

Correspondence should be addressed to K. F. Tamrin; tkfikri@unimas.my

Received 27 October 2017; Revised 26 December 2017; Accepted 9 January 2018; Published 4 March 2018

Academic Editor: Angela De Bonis

Copyright (c) 2018 K. F. Tamrin et al. This is an open access article distributed under the Creative Commons Attribution License, which permits unrestricted use, distribution, and reproduction in any medium, provided the original work is properly cited.

Extending the data transfer rates through dense interconnections at inter- and intraboard levels is a well-established technique especially in consumer electronics at the expense of more cross talk, electromagnetic interference (EMI), and power dissipation. Optical transmission using optical fibre is practically immune to the aforementioned factors. Among the manufacturing methods, UV laser ablation using an excimer laser has been repeatedly demonstrated as a suitable technique to fabricate multimode polymer waveguides. However, the main challenge is to precisely control and predict the topology of the waveguides without the need for extensive characterisation which is both time consuming and costly. In this paper, the authors present experimental results of investigation to relate the fluence, scanning speed, number of shots, and passes at varying pulse repetition rate with the depth of ablation of an acrylate-based photopolymer. The depth of ablation essentially affects total internal reflection and insertion loss, and these must be kept at minimum for a successful optical interconnection on printed circuit boards. The results are then used to predict depth of ablation for this material by means of adaptive neurofuzzy inference system (ANFIS) modelling. The predicted results, with a correlation of 0.9993 , show good agreement with the experimental values. This finding will be useful in better predictions along with resource optimisation and ultimately helps in reducing cost of polymer waveguide fabrication.

\section{Introduction}

Consumer electronics are experiencing uphill challenge to overcome high-frequency $(>10 \mathrm{~Gb} / \mathrm{s})$ transmission problems such as cross talk, electromagnetic interference, and power dissipation especially with high interconnectivity [1]. Rush for miniaturization, addition of more features/applications, and communication at microscales (e.g., chip-to-chip) have exposed the limits of copper-based transmissions in electronic circuits. To overcome this bottleneck, an optically enabled printed circuit board is a viable solution as this technique has been successfully used for long haul communications, that is, optical fiber. The optical interconnections (OIs), used in conjunction with copper connection thus forming electric-optical bridge, are usually made up of polymer waveguides. Various fabrication techniques of these polymer waveguides have been proposed including laser direct writing, photolithography, inkjet printing, and laser ablation [2]. Amongst all, laser ablation is the preferred technique for fabrication primarily due to its proven use as well as availability with PCB manufacturers $[1,2]$.

Laser-matter interaction and its suitability for machining various engineering materials, including various polymers [3-5], have been well researched and documented in the literature. Micromachining using IR (infrared) laser sources particularly using $\mathrm{CO}_{2}$ laser is common as it allows significantly higher rates of machining [6]. A few studies report the use of $\mathrm{CO}_{2}$ laser process for polymer waveguide 


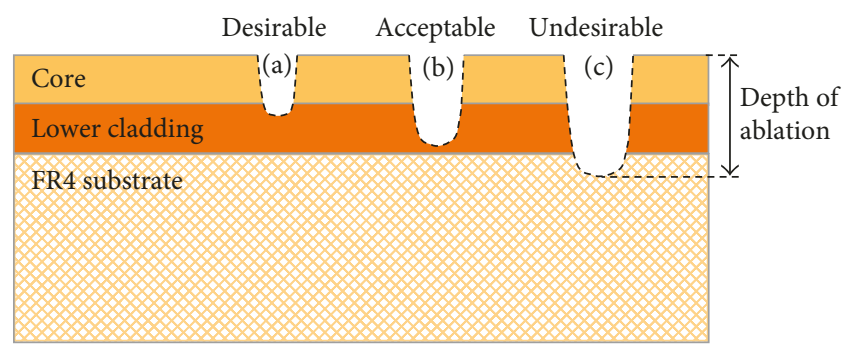

FIGURE 1: A schematic diagram showing three different types of ablation depths using laser beam with top-hat profile.

fabrications. In the pulsed mode, $\mathrm{CO}_{2}$ laser machining of PMMA (polymethyl methacrylate) waveguides was reported by Steenberge et al. [7]. Subsequently, an extensive study on a continuous wave (CW) $\mathrm{CO}_{2}$ laser processing of Truemode $^{\mathrm{TM}}$ polymer is detailed by Zakariyah et al. $[8,9]$. The study presented direct relationship between the depth of ablation and the scanning energy density while the width of the track was seen to vary logarithmically with the scanning energy density. In another study, submerged waveguides were demonstrated by Özcan et al. [10] using a $\mathrm{CW} \mathrm{CO}_{2}$ laser in planar silica films that showed reduction in the propagation loss.

In PCB manufacturing, the use of a $\mathrm{CO}_{2}$ laser is generally preferred, owing to its lower cost and availability. On the other hand, an excimer laser offers certain advantages by allowing machining of fine features at controllable rates. This process also ensures that there is less thermal damage on the ablated materials with minimum heat-affected zone (HAZ) dictated by, among other factors, a very high-absorption coefficient and short interaction between the laser and the ablated sample. The two key controlling parameters of this laser class are short wavelength and pulse duration. The former reduces the thermal diffusivity of the surface while the latter provides high-energy pulses. Furthermore high machining quality and ablation threshold are related to the pulse width duration of excimer laser [11]. Typical operating wavelengths of excimer lasers used for machining polymer materials especially for fabrication of optical waveguides are $193 \mathrm{~nm}$ (with $\mathrm{ArF}$ ) and $248 \mathrm{~nm}$ (with $\mathrm{KrF}$ ) [12].

Energy and pulse repetition rate (PRR) are two important process parameters highlighted by Steenberge et al. $[7,13,14]$ for the fabrication of waveguides in ORMOCER. It was observed that both parameters influence the smoothness of side walls of guides, which remains crucial for the propagation loss. In another study, Pfleging et al. [15] employed excimer laser to fabricate single-mode optical waveguides in PMMA. Following the method used for $\mathrm{CO}_{2}$ laser [10], Pfleging et al. selected UV fluences below the ablation threshold of PMMA. Another study conducted by Zakariyah et al. [11] showed good surface characteristics of excimer laser compared to $355 \mathrm{~nm}$ UV Nd:YAG and $10.6 \mu \mathrm{m} \mathrm{CO}$ lasers.

For long distance transmission of signal through the polymeric waveguides, total internal reflection is an important feature which is strongly influenced by the depth of ablation. As shown in Figure 1(a), it can be noted that minimum depth of ablation is desirable, although propagation of optical signal can be achieved by having scenario shown in Figure 1(b). However, further increase in depth of ablation can expose the cladding which means not only more laser power is utilized for the fabrication but also undesired thermal effects lead to increase the losses in the optical channel. This scenario is depicted in Figure 1(c) with possibility of severe damage to the FR4 substrate.

Apart from internal reflection, insertion loss is another main criterion for the optical interconnection. In fact, the prime measure of any optical waveguide is insertion loss which is strongly influenced by the depth of ablation as well as track width. Both depth of ablation and track width are mainly dependent on the laser processing parameters including laser power, rate of pulse repetition, focal distance, and scanning speed. Further investigation of these parameters is presented in forthcoming sections.

The ablation process for polymer waveguides using excimer laser is intricate involving several process parameters and material properties. Some researchers have suggested using techniques of soft computing to deal with these complexities $[6,8-10]$. These techniques are good at dissecting intricate problems with their features of nonlinearity and adaptability. For instance, artificial neural network (ANN) and fuzzy logic have been successfully utilized to predict complex system properties [16]. However, ANN has gained some untoward reviews due to its rather "black box" nature. On the other hand, taking the advantage of approximate reasoning, modelling techniques based on fuzzy logic have gained some attention. However, main bottleneck for this technique is the construction of membership functions (MFs). While combining both fuzzy logic and ANN, adaptive network-based fuzzy system takes full advantage of both techniques and eliminates their individual shortcomings [11]. This approach known as adaptive neurofuzzy inference system (ANFIS) imitates human thinking process and constructs input-output maps on human knowledge as well as the data pairs.

Several studies involving prediction of mechanical properties have found ANFIS predictions more reliable compared to ANN. For instance, results reported by Zare and Khaki [17] and Karaağaç et al. [18] showed that ANFIS performed better than ANN for predicting optimum values of their respective studies. Related to the use of ANFIS for laser micromachining, no such study could be found in literature especially for the fabrication of optical waveguides.

In the light of above discussion, this work has three main objectives: (1) experimental investigation of the use of $248 \mathrm{~nm}$ excimer laser for micromachining of optical polymer used in multimode polymer waveguides; (2) ANFIS modelling in prediction of ablation depth from the experimental data; and (3) comparison of ANFIS modelling with the result gained from the experiment. It is important to mention that it will be a first study of its kind to utilize ANFIS and compares the results with the experimental observations for acrylate-based photopolymer using UV excimer.

\section{Experimental Method}

2.1. Laser System. For this work, 7000 Series Exitech of $20 \mathrm{~ns}$ pulse krypton fluoride $(\mathrm{KrF})$ excimer laser $(\lambda=248 \mathrm{~nm})$ was used which could deliver up to $250 \mathrm{~mJ} /$ pulse. The size and 


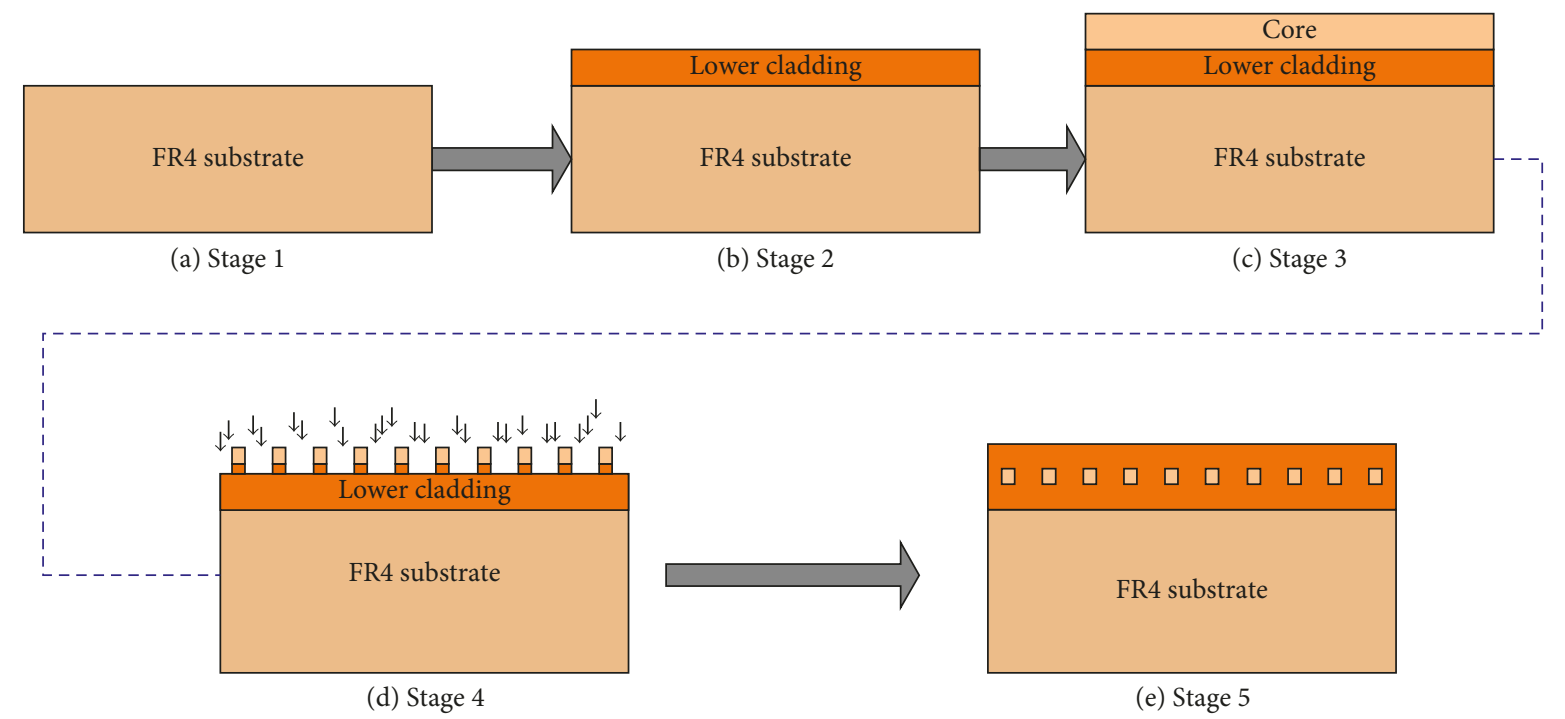

FIGURE 2: Key fabrication phases of laser ablation of multimode waveguides: (a) a base substrate of FR4, (b) formation of lower cladding by spin coating, (c) formation of the core layer, (d) laser ablation of the resulting sample from the core layer into the cladding layer, and (e) spin coating of the (optional) upper cladding.

shape of the beam were primarily determined by the mask dimension placed after the beam exit, which then passed through a $10 x$ projection lens. This allowed a focus beam spot to be obtained at the work piece for effective patterning of the samples. In the reported experiments, a TEM $\mathrm{TO}_{00}$ beam mode from the laser was masked by a square beam mask $\left(5 \times 5 \mathrm{~mm}^{2}\right)$ resulting in top-hat-like beam profile.

2.2. Optical Polymer Material. A UV-curable acrylate-based optical polymer from Exxelis Ltd (UK), commercially known as Truemode, was used. This is a light-yellow mixture of monomers and liquid at room temperature. Its low absorption loss, shown to be $<0.04 \mathrm{~dB} / \mathrm{cm}$ at $850 \mathrm{~nm}$ [15], supports its suitability for applications in optical interconnections. It is also shown to be compatible with standard printed circuit boards manufacturing process particularly at the high temperature and pressure involved. Following several trials of various formulations available from the supplier, authors selected EXX-core 37E and EXX-clad 277 formulations with indices of refraction of 1.5560 and 1.5265 , respectively. The refractive indices were measured at $850 \mathrm{~nm}$ wavelength, which is the same wavelength at which the optical propagation loss is measured for polymer waveguides.

2.3. Fabrication. Figure 2 shows the key fabrication phases employed in patterning a single layer optical waveguide (single- or mutimode), similar to what is reported in [19]. To summarise, the FR4 base substrate was decontaminated from debris by cleaning in water (or methanol) and was allowed to get fully dry in an oven. Optical layers (core and cladding) were thereafter formed on FR4 by spin coating Truemode at approximately $350 \mathrm{rev} / \mathrm{min}$ for $30 \mathrm{sec}$. The lower cladding was spun and UV cured initially in $\mathrm{N}_{2}$ environment under UV light for $200 \pm 40 \mathrm{sec}$. This is followed by spin coating the core layer. At this stage, the whole sample of FR4-clad-core was UV cured again for complete crosslinking and subsequently oven-baked at a temperature of $100^{\circ} \mathrm{C}$ for 60 minutes. The obtained thickness in each case (core or cladding layer) was $40 \pm 10$ microns. As the core and cladding layers are essentially made from the same materials with a slight difference in the refractive index as previously indicated, their interaction with the laser and the absorption coefficient is expected to be similar. Therefore, nothing unusual was observed in the interface of these layers. Generally, the fabrication of polymer waveguides was followed by an extensive system characterisation, and as a result, the steps are same whether the ultimate goal was to fabricate or to characterise the depth of ablation. This is to ensure that data obtained during the characterisation can be implemented for the fabrication phase without undue adjustment to the setting.

\section{Prediction of Depth of Ablation by Means of Adaptive Neurofuzzy Inference System (ANFIS)}

In this study, an adaptive neurofuzzy inference system (ANFIS) is adopted to predict the depth of ablation as a function of five input variables using experimental data listed in Table 1. An ANFIS is an adaptive network which combines fuzzy logic and neural network system to develop the prediction model based on the input knowledge. The ANFIS was first introduced by Jang in 1993 [20], and functionally it is similar to the Takagi-Sugeno-type inference model. To diligently adjust the membership function of the fuzzy inference system (FIS), the ANFIS employs the least squares method and back-propagation gradient descent method from neural network [21]. Figure 3 illustrates a general ANFIS architecture assuming two inputs, namely, $x$ and $y$ and one output, namely, $f$. The architecture typically has five different layers characterized by adaptive and fixed 
TABLE 1: Experimental layout and results.

\begin{tabular}{|c|c|c|c|c|c|c|c|}
\hline \multirow[b]{2}{*}{ Experiment } & \multicolumn{5}{|c|}{ Processing parameter } & \multicolumn{2}{|c|}{ Response } \\
\hline & $\begin{array}{l}\text { Number of } \\
\text { shots }\end{array}$ & $\begin{array}{l}\text { Fluence } \\
\left(\mathrm{J} / \mathrm{cm}^{2}\right)\end{array}$ & $\begin{array}{l}\text { Scanning speed } \\
(\mathrm{mm} / \mathrm{min})\end{array}$ & $\begin{array}{c}\text { Pulse repetition } \\
\text { rate }(\mathrm{Hz})\end{array}$ & $\begin{array}{c}\text { Number of } \\
\text { passes }\end{array}$ & $\begin{array}{l}\text { Maximum depth } \\
(\mu \mathrm{m}) / 1 \text { shot }\end{array}$ & $\begin{array}{l}\text { Mean depth } \\
(\mu \mathrm{m}) / 1 \text { shot }\end{array}$ \\
\hline 1 & 1 & 0.086 & 120 & 20 & 1 & 0.799 & 0.678 \\
\hline 2 & 2 & 0.086 & 60 & 20 & 1 & 1.86 & 1.65 \\
\hline 3 & 3 & 0.086 & 40 & 20 & 1 & 2.79 & 2.49 \\
\hline 4 & 4 & 0.086 & 30 & 20 & 1 & 3.53 & 3.12 \\
\hline 5 & 5 & 0.086 & 24 & 20 & 1 & 4.56 & 4.04 \\
\hline 6 & 6 & 0.086 & 20 & 20 & 1 & 5.73 & 5.15 \\
\hline 7 & 7 & 0.086 & 17.1 & 20 & 1 & 6.30 & 5.53 \\
\hline 8 & 8 & 0.086 & 15 & 20 & 1 & 7.08 & 6.2 \\
\hline 9 & 9 & 0.086 & 13.3 & 20 & 1 & 7.59 & 6.61 \\
\hline 10 & 10 & 0.086 & 12 & 20 & 1 & 8.81 & 7.63 \\
\hline 11 & 12 & 0.086 & 10 & 20 & 1 & 9.75 & 8.5 \\
\hline 12 & 14 & 0.086 & 8.57 & 20 & 1 & 12.0 & 10.4 \\
\hline 13 & 16 & 0.086 & 7.5 & 20 & 1 & 13.1 & 11.4 \\
\hline 14 & 18 & 0.086 & 6.67 & 20 & 1 & 14.9 & 13.1 \\
\hline 15 & 20 & 0.086 & 6 & 20 & 1 & 16.6 & 14.5 \\
\hline 16 & 22 & 0.086 & 5.45 & 20 & 1 & 19.3 & 17 \\
\hline 17 & 24 & 0.086 & 5 & 20 & 1 & 20.0 & 17.5 \\
\hline 18 & 26 & 0.086 & 4.62 & 20 & 1 & 21.8 & 18.9 \\
\hline 19 & 28 & 0.086 & 4.29 & 20 & 1 & 22.9 & 20.2 \\
\hline 20 & 30 & 0.086 & 4 & 20 & 1 & 24.2 & 21 \\
\hline 21 & 10 & 0.03 & 6 & 10 & 1 & 0.252 & 0.173 \\
\hline 22 & 10 & 0.058 & 6 & 10 & 1 & 0.516 & 0.425 \\
\hline 23 & 10 & 0.086 & 6 & 10 & 1 & 0.797 & 0.695 \\
\hline 24 & 10 & 0.113 & 6 & 10 & 1 & 1.11 & 0.988 \\
\hline 25 & 10 & 0.141 & 6 & 10 & 1 & 1.46 & 1.35 \\
\hline 26 & 10 & 0.169 & 6 & 10 & 1 & 1.79 & 1.66 \\
\hline 27 & 10 & 0.197 & 6 & 10 & 1 & 1.96 & 1.82 \\
\hline 28 & 10 & 0.224 & 6 & 10 & 1 & 2.19 & 2.04 \\
\hline 29 & 10 & 0.252 & 6 & 10 & 1 & 2.3 & 2.17 \\
\hline 30 & 10 & 0.28 & 6 & 10 & 1 & 2.5 & 2.36 \\
\hline 31 & 1 & 0.086 & 120 & 20 & 3 & 2.79 & 2.43 \\
\hline 32 & 1 & 0.086 & 120 & 20 & 4 & 3.9 & 3.1 \\
\hline 33 & 1 & 0.086 & 120 & 20 & 5 & 4.1 & 3.42 \\
\hline 34 & 1 & 0.086 & 120 & 20 & 9 & 8.6 & 7.58 \\
\hline 35 & 1 & 0.086 & 120 & 20 & 10 & 10.0 & 8.47 \\
\hline 36 & 1 & 0.086 & 72 & 12 & 1 & 1.07 & 0.967 \\
\hline
\end{tabular}

nodes. As highlighted in Figure 3, the output of each layer (layers 2-5) is used as the input to the succeeding layer.

The first layer is the adaptive node layer or commonly known as the fuzzification layer, where membership functions (generalized bell, Gaussian, or triangular) are designated. In this layer, bell-shaped membership function can be selected with the maximum value of 1.0 and minimum value of 0.0 . The function can be written as

$$
\mu A_{i}(x)=\frac{1}{1+\left[\left(\left(x-c_{i}\right) /\left(a_{i}\right)\right)^{2}\right] b_{i}},
$$

where $a_{i}, b_{i}$, and $c_{i}$ are a set of parameters and $\mu A_{i}(x)$ is the membership function corresponding to the input parameter $x$. Accordingly, the function $\mu A_{i}(x)$ changes as $a_{i}, b_{i}$, and $c_{i}$ vary.

Each node in the second layer is nonadaptive (fixed), and it acts as the fuzzy "AND" operator in the premise section of the fuzzy if-then rule. In other words, it multiplies the incoming signals, and the output represents the firing (operating) strength of each fuzzy rule. For example,

$$
W_{i}=\mu A_{i}(x) \mu B_{i}(y), \quad i=1,2,
$$




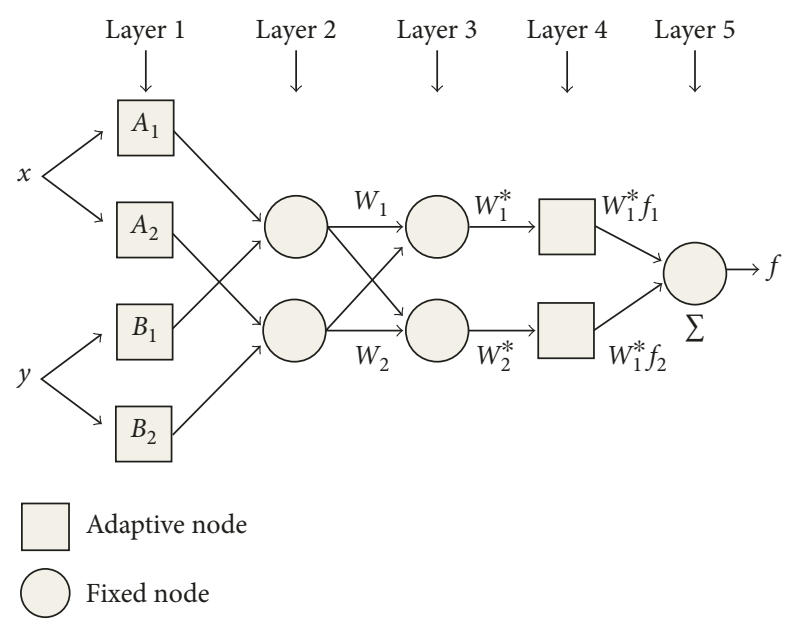

FIgURE 3: Typical ANFIS architecture for two inputs and one output.

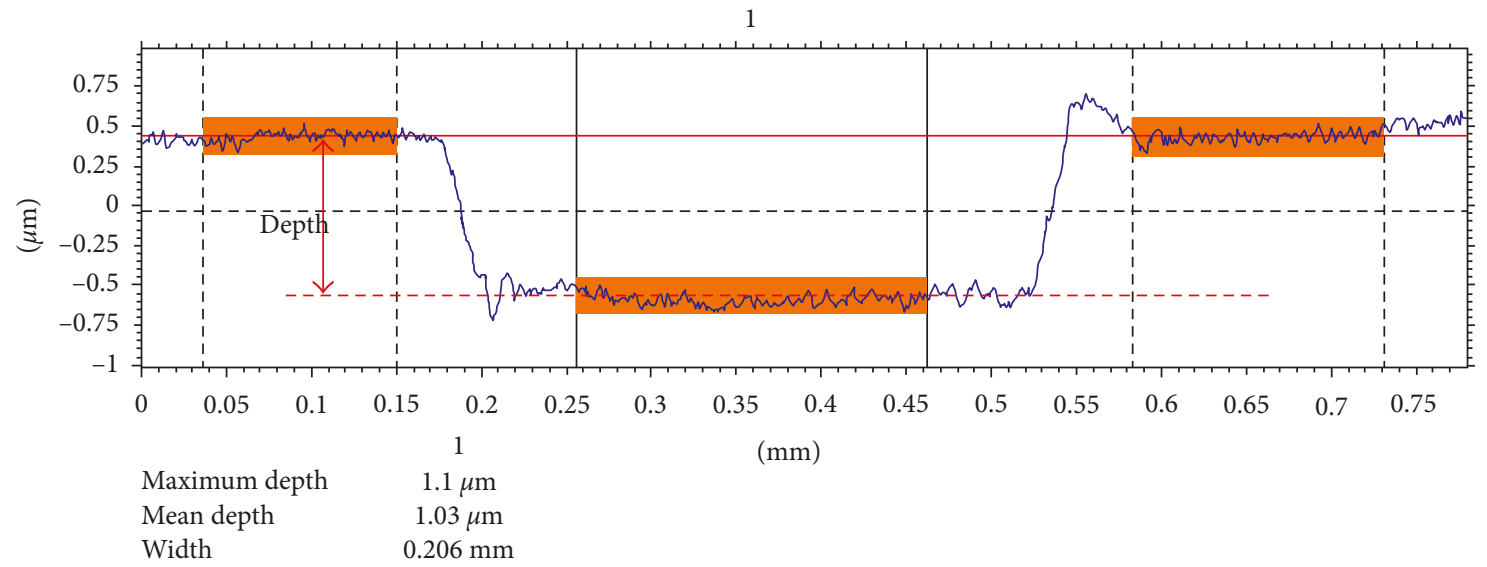

Figure 4: Screenshot of depth measurement using Talysurf CLI scanning topography-measuring instrument. The instrument gives values of maximum and mean depths of ablation and width of ablation.

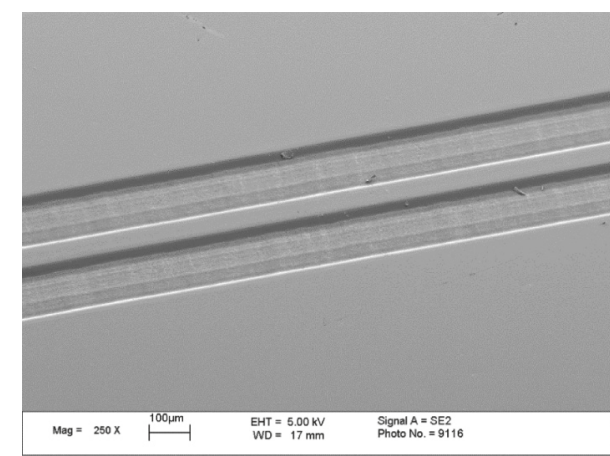

(a)

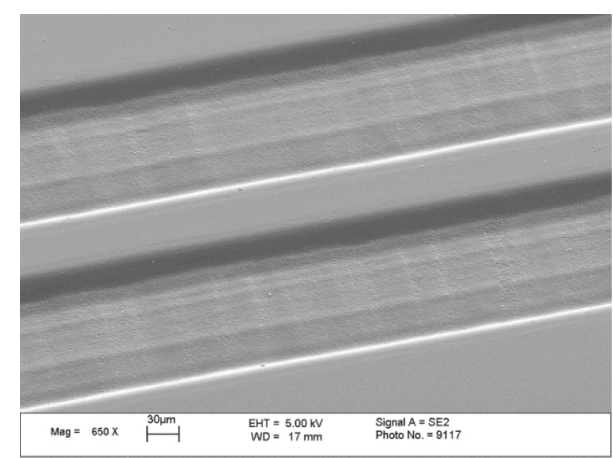

(b)

FIGURE 5: SEM images of ablated depth at (a) 250x and (b) 650x magnifications (sample number 61: number of shots=45, fluence $=0.1 \mathrm{~J} / \mathrm{cm}^{2}$, scanning speed $=3.3 \mathrm{~mm} / \mathrm{min}$, and pulse repetition rate $=25 \mathrm{~Hz}$ ). Measured maximum and mean depths are $1.002 \mu \mathrm{m}$ and $0.740 \mu \mathrm{m}$, respectively.

where $W_{i}$ is the weight function for the next layer and $\mu B_{i}(y)$ is the membership function corresponding to the input parameter $y$.
The third layer is also a nonadaptive layer which is also known as the normalized layer. It serves to calculate the normalized firing strength in (2) using the following equation [22]: 


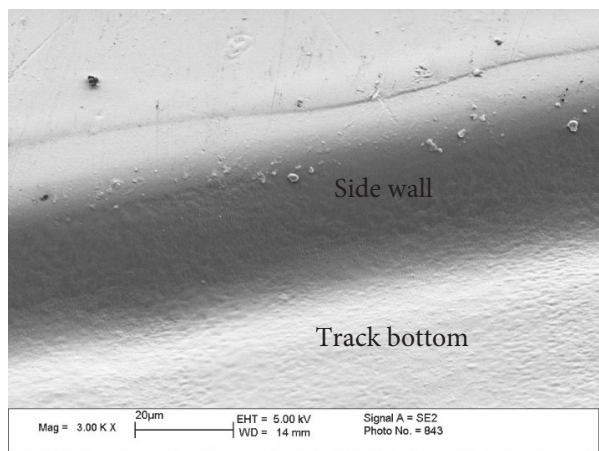

(a)

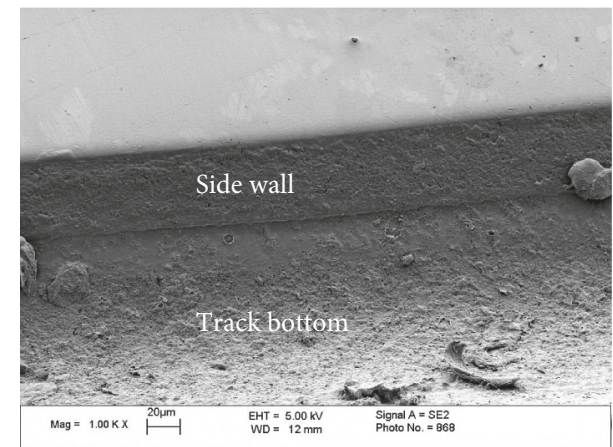

(b)

FIGURE 6: Surface roughness comparison of ablation tracks machined using (a) excimer (sample number 116 line 5) and (b) $\mathrm{CO}_{2}$ (sample A1) lasers.

$$
W_{i}^{*}=\frac{W_{i}}{W_{1}+W_{2}}, \quad i=1,2,
$$

The fourth layer consists of adaptive nodes. This layer estimates the contribution of each input parameter towards the overall output. This is carried out by the assignment of weights to minimize the deviation between outputs and desired results. The relation between inputs $x$ and $y$ and output $f$ can be defined as

$$
W_{i}^{*} f_{i}=W_{i}^{*}\left(p_{i} x+q_{i} y+r_{i}\right), \quad i=1,2,
$$

where $p_{i}, q_{i}$, and $r_{i}$ are the linear parameters or consequent parameters, and they can be adjusted in the training process.

The fifth layer is the defuzzification (output) layer and essentially the summation of all fourth layer signals. The output, $f$, can be computed by the following equation:

$$
f=\frac{\sum_{i} W_{i}^{*} f_{i}}{\sum_{i} W_{i}^{*}}, \quad i=1,2 .
$$

\section{Results and Discussion}

Typical and essential stages involved in multimode polymer waveguide fabrication were followed, and effect of process parameters on the prepared samples were analysed and measured. Before measurement, the ablated samples were first sectioned (using Buehler IsoMet ${ }^{\circledR}$ low-speed saw) and then polished using abrasives ( $1 \mu \mathrm{m}$ diamond paste). Ablated depths of channels were measured using the SmartScope ${ }^{\circledR}$ Flash $^{\mathrm{TM}} 200$ optical measuring device. The device has a traverse length of $200 \times 200 \times 150 \mathrm{~mm}$ with a resolution of $0.5 \mu \mathrm{m}$. Topographic measurements were carried out using a single point sensor gauge of the Talysurf CLI scanner which can travel up to a maximum speed of $20 \mathrm{~mm} / \mathrm{s}$. The latter instrument took measurements across the channel at equal intervals along the channel, and it automatically calculated the respective mean and maximum depths of ablation. The experimental results are given in Table 1. A total of 36 experiments were designed. It should be noted that the effect of all individual processing parameters on the response parameters were studied separately while keeping other parameters constant.
TABLE 2: Mean prediction error for different types of membership functions.

\begin{tabular}{lc}
\hline Membership function & Mean prediction error (\%) \\
\hline Triangular (trimf) & 4.194 \\
Generalized bell (gbellmf) & 1.991 \\
Gaussian (gaussmf) & 2.183 \\
Trapezoidal (trapmf) & 3.233 \\
\hline
\end{tabular}

As shown in Figures 4 and 5, the ablated section resembles the top-hat beam profile with some tapering effect on both edges (slightly tapered side walls). One method to lower the tapering at high fluence $\left(\sim 2 \mathrm{~J} \cdot \mathrm{cm}^{-2}\right)$, as suggested in [23], is by increasing the number of shots. However, despite the investigation, no conclusion can be drawn on the significance of these factors on the tapering effect seen in the ablated profile. Furthermore, some of the observed tapering effects can be linked to the focus position of laser as evident in laser system characterisation.

As earlier, it is pointed out that the use of excimer laser is preferred as it is readily absorbed by the polymers and causes minimum thermal load and damage to the surroundings. In this study, UV pulses of 10-35 ns in length were used which produced relatively clean ablation with little thermal damage to surroundings, as shown in Figure 6(a). On the other hand, high processing speed of its counterpart IR $\mathrm{CO}_{2}$ laser resulted in large $\mathrm{HAZ}$ which is undesirable and may influence the propagation losses in the waveguide (Figure 6(b)). However, slow speed and high operating costs of excimer laser and the use of fluorine gas (toxic in nature) are main reasons of its lesser acceptance in the PCB industry. The last factor can be easily overcome by putting in place engineering and administrative controls while the effects of others can also be minimised.

For the ANFIS architecture, five inputs for the network are used. Number of shots, fluence, scanning speed, pulse repetition rate, and number of passes are the processing parameters, while the depth of ablation is the measured output. In the present work, the experimental data were divided into two groups for the purpose of training and subsequent testing. The first 27 data from Table 1 were chosen to be the training samples, while the remaining data were used to be the testing samples ( 9 samples).

In the beginning, a triangular-shaped membership function was selected for each input variable in ANFIS architecture. 


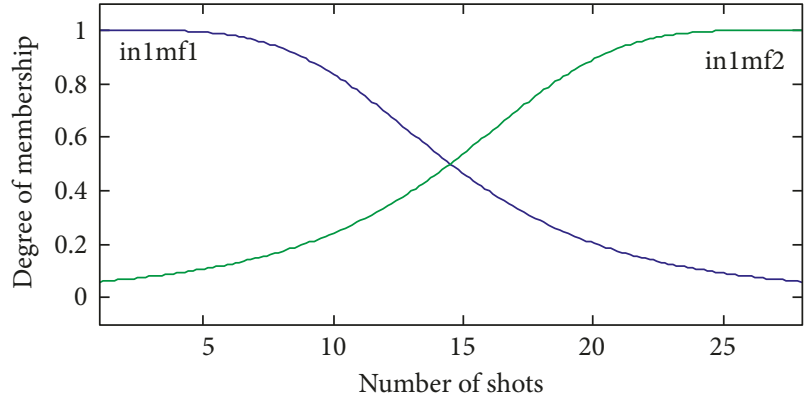

(a)

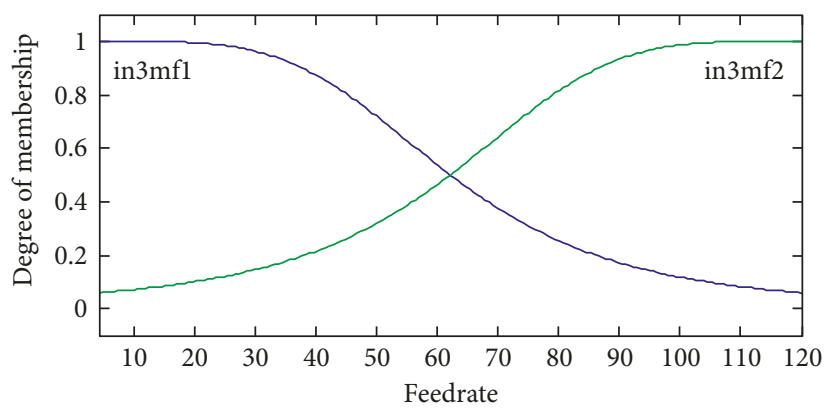

(c)

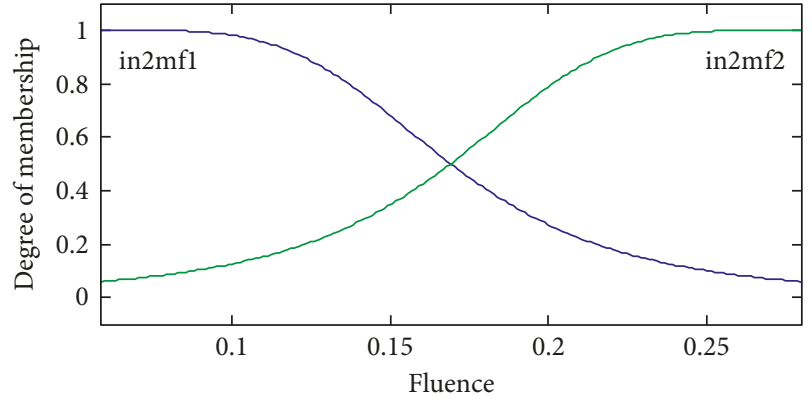

(b)

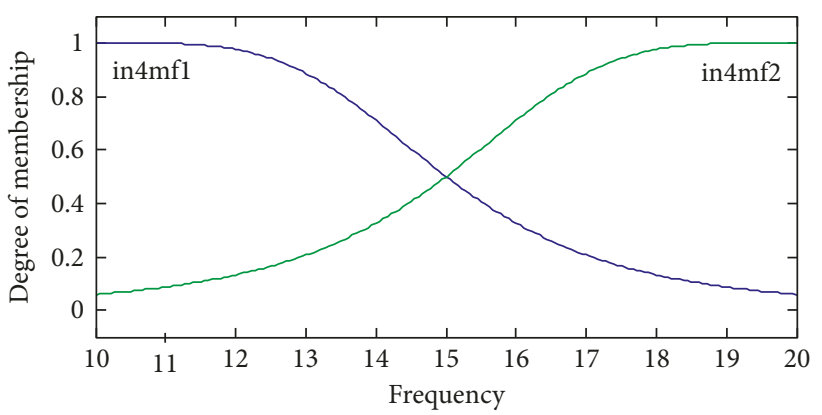

(d)

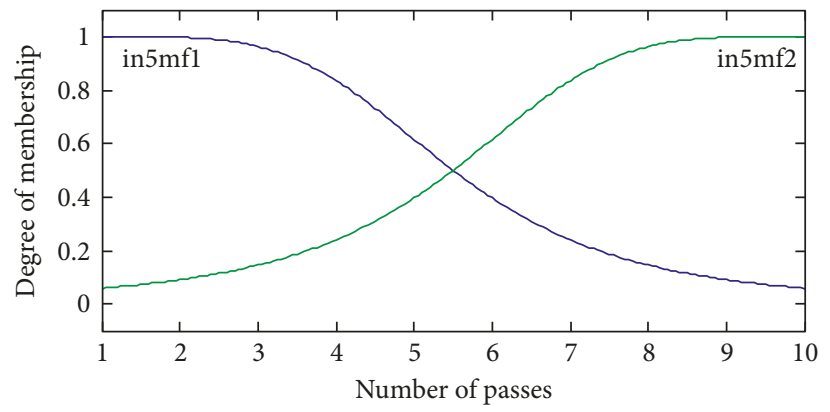

(e)

Figure 7: Membership function diagrams based on generalized bell for all inputs: (a) number of shots, (b) fluence, (c) scanning speed, (d) pulse repetition rate, and (e) number of passes.

Subsequently, different types of membership function were evaluated, that is, generalized bell, Gaussian, and trapezoidal. A Sugeno-type FIS structure was chosen to initialize the membership function parameters for ANFIS training, and the output membership function was set to be linear.

Equations (4) and (5) were used to predict the outputs which help in training the ANFIS model. Weights and thresholds at different layers were adjusted using the backpropagation algorithm relying on the gradient search technique. Weights were adjusted in order to minimize the mean-squared error between the experimental and predicted results. The training phase required some initial estimation of ANFIS parameters such as type of membership functions for each input variable and fuzzy rule. For instance, Table 2 shows results of the mean prediction error for four different types of membership functions. Due to its lowest percentage of error, the generalized bell function was chosen for both training and testing (Figure 7). After the training of the AFNIS model is completed, the model can be utilized to predict the depth of ablation. A complete comparison of the predicted and experimentally measured depth of ablation is shown in Table 3 and Figure 8.

It is important to mention that the mean relative error for the present ANFIS is comparable to the findings in the literature. For instance, Jia et al. [24] acquired 5.23\% mean relative error for 30 sets of experiments, while Zare and Khaki [17] managed to obtain much lesser mean relative error of $1.62 \%$ for 10 sets of experiments. ANFIS prediction for the present work can be considered comparatively accurate since the training data extensively cover the complete range of parameters. Based on Figure 8, experiment numbers 6 and 33 show considerably large prediction errors of $7.934 \%$ and $16.371 \%$, respectively. Nevertheless, the predicted values remain below the measured maximum depths of ablation. Figure 9 graphically compares experiment and predicted depth of ablations based on regression analysis. It is clear that the predicted ANFIS results compare well with the experimental results with the correlation coefficient $\left(R^{2}\right)$ value up to 0.9993 . 
TABLE 3: Comparison of experimental and predicted mean depths and their relative errors.

\begin{tabular}{|c|c|c|c|}
\hline Experiment & $\begin{array}{c}\text { Experimental } \\
\text { mean depth }(\mu \mathrm{m})\end{array}$ & $\begin{array}{l}\text { Predicted mean } \\
\text { depth }(\mu \mathrm{m})\end{array}$ & $\begin{array}{l}\text { \% relative } \\
\text { error } \\
(\text { gbellmf })\end{array}$ \\
\hline 1 & 0.678 & 0.702 & 3.496 \\
\hline 2 & 1.65 & 1.651 & 0.055 \\
\hline 3 & 2.49 & 2.474 & 0.655 \\
\hline 4 & 3.12 & 3.184 & 2.035 \\
\hline 5 & 4.04 & 3.979 & 1.505 \\
\hline 6 & 5.15 & 4.741 & 7.934 \\
\hline 7 & 5.53 & 5.437 & 1.689 \\
\hline 8 & 6.2 & 6.139 & 0.981 \\
\hline 9 & 6.61 & 6.782 & 2.604 \\
\hline 10 & 7.63 & 7.442 & 2.461 \\
\hline 11 & 8.5 & 8.752 & 2.964 \\
\hline 12 & 10.4 & 10.168 & 2.234 \\
\hline 13 & 11.4 & 11.721 & 2.818 \\
\hline 14 & 13.1 & 13.333 & 1.779 \\
\hline 15 & 14.5 & 14.914 & 2.852 \\
\hline 16 & 17 & 16.398 & 3.544 \\
\hline 17 & 17.5 & 17.740 & 1.372 \\
\hline 18 & 18.9 & 18.976 & 0.404 \\
\hline 19 & 20.2 & 20.142 & 0.287 \\
\hline 20 & 21 & 21.250 & 1.190 \\
\hline 21 & 0.173 & 0.174 & 0.405 \\
\hline 22 & 0.425 & 0.428 & 0.612 \\
\hline 23 & 0.695 & 0.691 & 0.576 \\
\hline 24 & 0.988 & 0.988 & 0.040 \\
\hline 25 & 1.35 & 1.356 & 0.437 \\
\hline 26 & 1.66 & 1.652 & 0.494 \\
\hline 27 & 1.82 & 1.851 & 1.720 \\
\hline 28 & 2.04 & 2.017 & 1.132 \\
\hline 29 & 2.17 & 2.184 & 0.641 \\
\hline 30 & 2.36 & 2.350 & 0.415 \\
\hline 31 & 2.43 & 2.348 & 3.370 \\
\hline 32 & 3.1 & 3.164 & 2.068 \\
\hline 33 & 3.42 & 3.980 & 16.371 \\
\hline 34 & 7.58 & 7.556 & 0.322 \\
\hline 35 & 8.47 & 8.489 & 0.218 \\
\hline 36 & 0.967 & 0.967 & 0.000 \\
\hline
\end{tabular}

Mean relative error $=1.991$.

\section{Conclusions}

This paper experimentally investigates the effects of varying laser processing parameters on the depth of ablation of optical polymer waveguides. Laser ablation using excimer laser results in a cleaner and smoother ablated structures with minimal thermal damage to the surroundings. However, due to slow speed and high operating costs of the excimer laser, there is a need for a mechanism to accurately predict and estimate the ablation depth of the optical waveguides for various input parameters. Here, an adaptive neurofuzzy

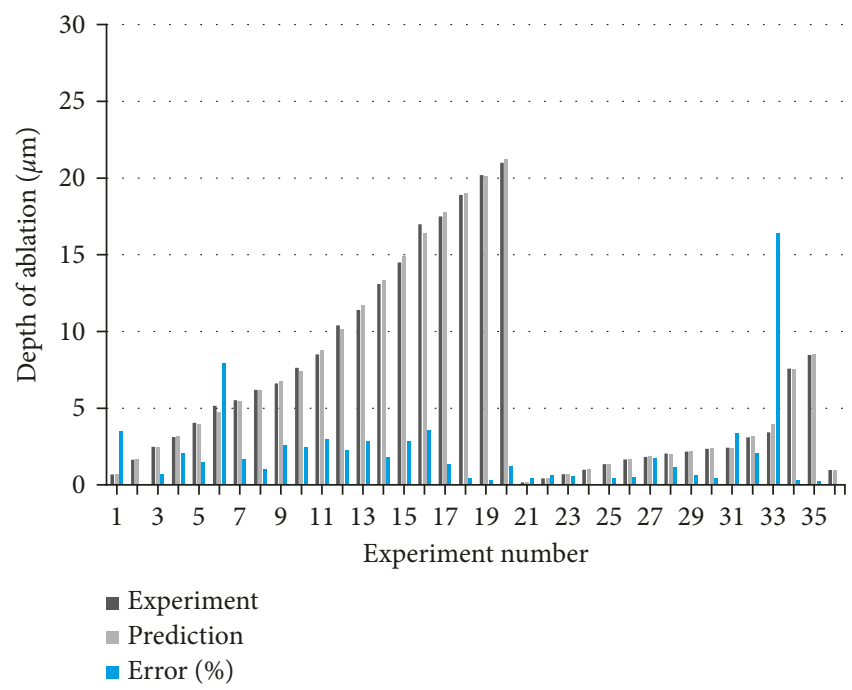

Figure 8: Graph comparing experiment and predicted depth of ablation including error prediction.

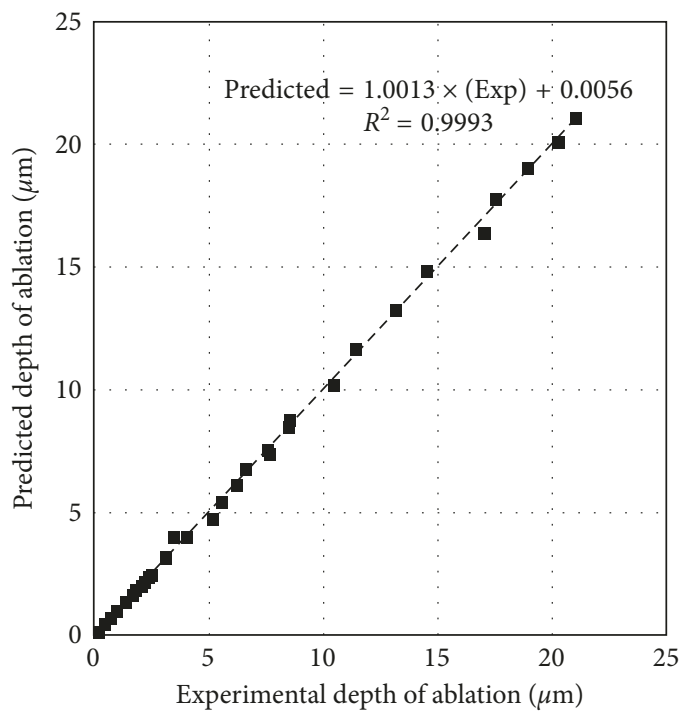

FIgURE 9: Experimental and ANFIS model-predicted depth of ablation plotted for the best model developed using five input variables.

inference system (ANFIS) model is proposed and applied to a series of experimental datasets. The trained ANFIS model predicts the ablation depth with an accuracy of $R^{2}=0.9993$ and a mean prediction error of $1.991 \%$. It has been shown that with the aid of the ANFIS, a multiple input/single output fuzzy inference system can be created that accurately characterizes the ablation depth of optical polymer waveguides.

\section{Conflicts of Interest}

The authors declare that they have no conflicts of interest.

\section{Acknowledgments}

The initial result of the work reported here was part of the Integrated Optical and Electronic Interconnect $\mathrm{PCB}$ 
Manufacturing (OPCB) IeMRC Flagship Project FS/06/01/01, financially supported by the UK Engineering and Physical Sciences Research Council (EPSRC) through the Innovative Electronics Manufacturing Research Centre (IeMRC). The modelling work is supported by the Ministry of Higher Education Malaysia under Grant no. F02/FRGS/1619/2017. The authors are also grateful for the technical input of the 8 collaborating companies and three universities (Loughborough University, University College London, and Heriot-Watt University) who were partners in the consortium, and special thanks are due to Khadijah Olaniyan for helpful discussions.

\section{References}

[1] M. C. Gower, "Industrial applications of laser micromachining," Optics Express, vol. 7, no. 2, pp. 56-67, 2000.

[2] K. Yung, D. Zeng, and T. Yue, "XPS investigation of Upilex-S polyimide ablated by $355 \mathrm{~nm}$ Nd: YAG laser irradiation," Applied Surface Science, vol. 173, no. 3-4, pp. 193-202, 2001.

[3] K. Tamrin, Y. Nukman, and S. Zakariyah, "Laser lap joining of dissimilar materials: a review of factors affecting joint strength," Materials and Manufacturing Processes, vol. 28, no. 8, pp. 857-871, 2013.

[4] K. Tamrin, Y. Nukman, N. A. Sheikh, and M. Z. Harizam, "Determination of optimum parameters using grey relational analysis for multi-performance characteristics in $\mathrm{CO}_{2}$ laser joining of dissimilar materials," Optics and Lasers in Engineering, vol. 57, pp. 40-47, 2014.

[5] K. Tamrin, Y. Nukman, and N. Sheikh, "Laser spot welding of thermoplastic and ceramic: an experimental investigation," Materials and Manufacturing Processes, vol. 30, no. 9, pp. 1138-1145, 2015.

[6] K. Tamrin, Y. Nukman, I. A. Choudhury, and S. Shirley, "Multiple-objective optimization in precision laser cutting of different thermoplastics," Optics and Lasers in Engineering, vol. 67, pp. 57-65, 2015.

[7] G. Van Steenberge, P. Geerinck, S. Van Put, and P. Van Daele, "Integration of multimode waveguides and micromirror couplers in printed circuit boards using laser ablation," in Proceedings of the Photonics Europe, International Society for Optics and Photonics, Strasbourg, France, April 2004.

[8] K. Tamrin, S. Zakariyah, and N. Sheikh, "Multi-criteria optimization in $\mathrm{CO}_{2}$ laser ablation of multimode polymer waveguides," Optics and Lasers in Engineering, vol. 75, pp. 48-56, 2015.

[9] S. S. Zakariyah, P. P. Conway, D. A. Hutt, K. Wang, and D. R. Selviah, " $\mathrm{CO}_{2}$ laser micromachining of optical waveguides for interconnection on circuit boards," Optics and Lasers in Engineering, vol. 50, no. 12, pp. 1752-1756, 2012.

[10] L. Ç. Özcan, F. Guay, R. Kashyap, and L. Martinu, "Fabrication of buried waveguides in planar silica films using a direct CW laser writing technique," Journal of Non-Crystalline Solids, vol. 354, no. 42, pp. 4833-4839, 2008.

[11] S. S. Zakariyah, P. P. Conway, D. A. Hutt et al., "Polymer optical waveguide fabrication using laser ablation," in Proceedings of the 11th Electronics Packaging Technology Conference EPTC'09, Singapore, December 2009.

[12] Y.-T. Chen, K. Naessens, R. Baets, Y.-S. Liao, and A. A. Tseng, "Ablation of transparent materials using excimer lasers for photonic applications," Optical Review, vol. 12, no. 6, pp. 427-441, 2005.

[13] N. Hendrickx, G. Van Steenberge, P. Geerinck, and P. Van Daele, "Laser ablation as enabling technology for the structuring of optical multilayer structures," Journal of Physics: Conference Series, vol. 59, pp. 118-121, 2007.

[14] G. Van Steenberge, P. Geerinck, S. Van Put et al., "MTcompatible laser-ablated interconnections for optical printed circuit boards," Journal of Lightwave Technology, vol. 22, no. 9, pp. 2083-2090, 2004.

[15] W. Pfleging, M. Przybylski, and H. Brückner, "Excimer laser material processing-state of the art and new approaches in microsystem technology," in Proceedings of the SPIE, Europe, July 2006.

[16] A. Hossain, A. Hossain, Y. Nukman et al., "A fuzzy logicbased prediction model for kerf width in laser beam machining," Materials and Manufacturing Processes, vol. 31, no. 5, pp. 679-684, 2016.

[17] M. Zare and J. V. Khaki, "Prediction of mechanical properties of a warm compacted molybdenum prealloy using artificial neural network and adaptive neuro-fuzzy models," Materials \& Design, vol. 38, pp. 26-31, 2012.

[18] B. Karaağaç, M. İnal, and V. Deniz, "Predicting optimum cure time of rubber compounds by means of ANFIS," Materials \& Design, vol. 35, pp. 833-838, 2012.

[19] S. S. Zakariyah, P. P. Conway, D. A. Hutt et al., "Fabrication of polymer waveguides by laser ablation using a $355 \mathrm{~nm}$ wavelength Nd: YAG laser," Journal of Lightwave Technology, vol. 29, no. 23, pp. 3566-3576, 2011.

[20] J.-S. Jang, “ANFIS: adaptive-network-based fuzzy inference system," IEEE transactions on systems, man, and cybernetics, vol. 23, no. 3, pp. 665-685, 1993.

[21] H. B. Demuth, M. T. Hagan, M. Hudson Beale, and O. De Jesús, Neural Network Design, Martin Hagan, 2014.

[22] S. S. Roy, "Design of adaptive neuro-fuzzy inference system for predicting surface roughness in turning operation," Journal of Scientific and Industrial Research, vol. 64, no. 9, p. 653, 2005.

[23] N. Bityurin, "8 Studies on laser ablation of polymers," Annual Reports Section "C" (Physical Chemistry), vol. 101, pp. 216-247, 2005.

[24] W. Jia, W. Zeng, Y. Han, J. Liu, Y. Zhou, and Q. Wang, "Prediction of flow stress in isothermal compression of Ti60 alloy using an adaptive network-based fuzzy inference system," Materials \& Design, vol. 32, no. 10, pp. 4676-4683, 2011. 


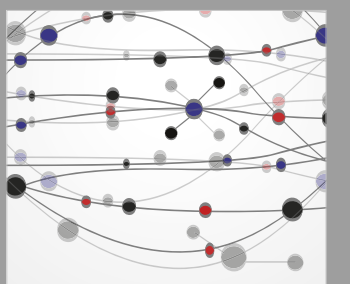

The Scientific World Journal
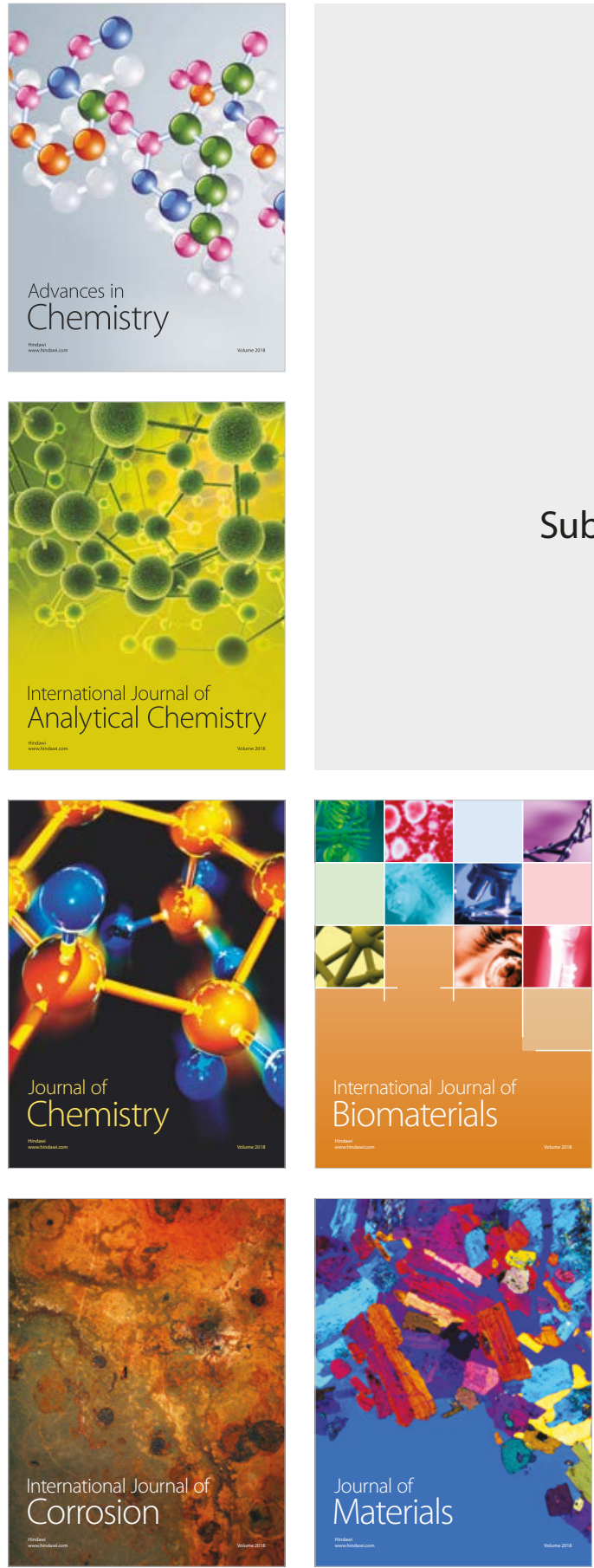

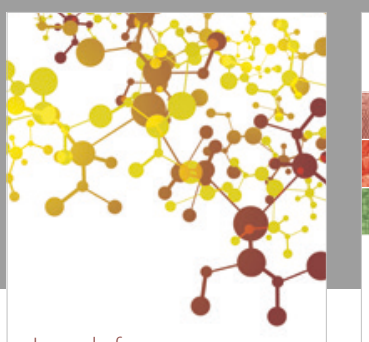

Journal of

Applied Chemistry
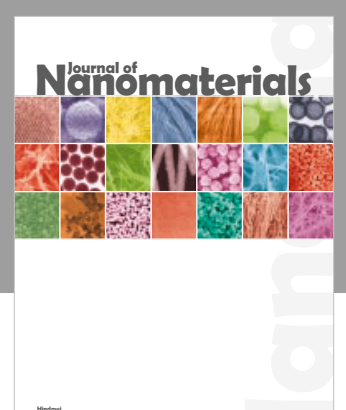

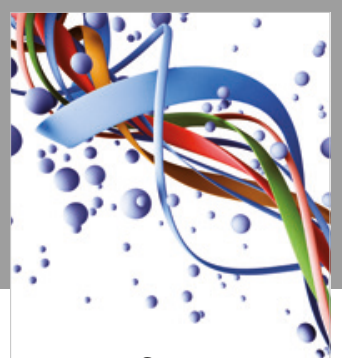

Scientifica

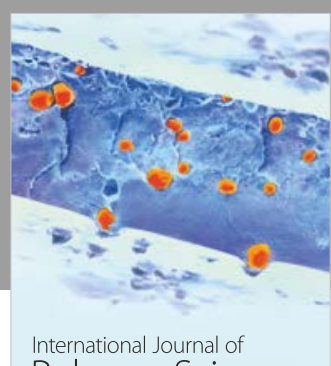

Polymer Science

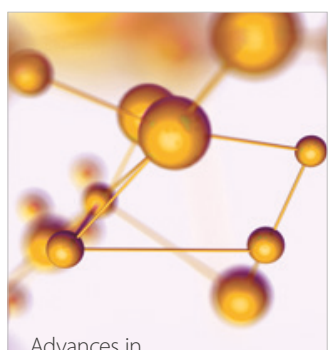

Physical Chemistry
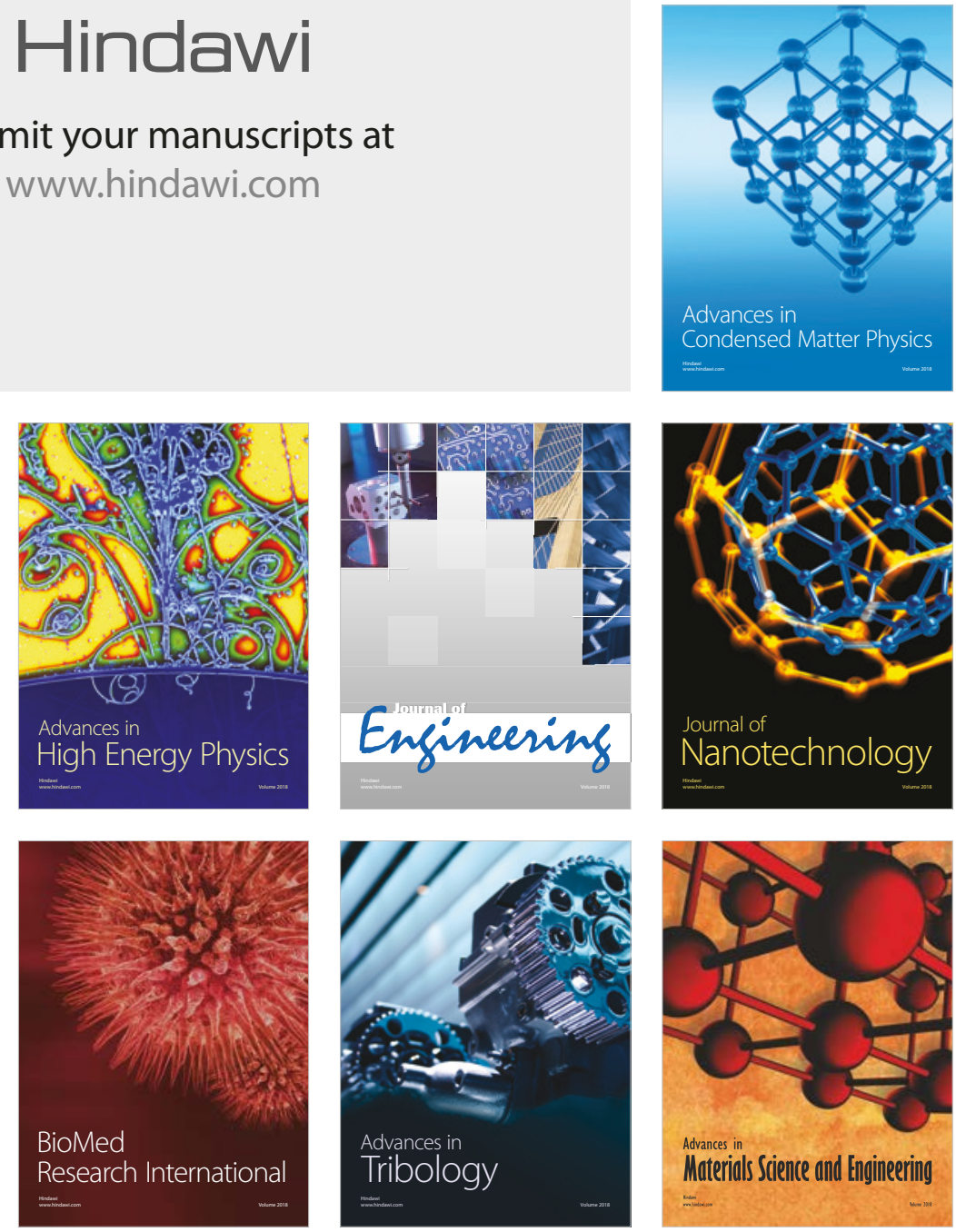